\title{
Modelling and Simulation of PtG Plant Start-Ups and Shutdowns
}

\author{
Teemu Sihvonen $^{1} \quad$ Jouni Savolainen $^{2} \quad$ Matti Tähtinen $^{1}$ \\ ${ }^{1}$ Renewable energy processes, VTT Technical Research Centre of Finland Ltd., Jyväskylä, Finland, \\ \{teemu.sihvonen, matti.tahtinen\}@vtt.fi \\ ${ }^{2}$ VTT Technical Research Centre of Finland Ltd., Espoo, Finland, jouni .savolainen@vtt. fi
}

\begin{abstract}
As the share of renewable energy sources increases the need for energy storages increases also due to fluctuating nature of renewables (solar and wind). Power-to-Gas $(\mathrm{PtG})$ is one a promising energy storing concept. In PtG process renewable electric energy is used to produce hydrogen via electrolysis. Hydrogen is used together with carbon dioxide in methanation process to produce storable methane. Automation and operation logics of PtG plant have been in the minority in the literature. In this work we have studied start-up and shutdown logics of a PtG plant with dynamic simulations. With this approach we have identified development needs for such logics
\end{abstract}

Keywords: power-to-gas, automation, start-up, shutdown

\section{Introduction}

In the Paris Agreement 2015 governments have agreed to a long-term goal in global average temperature increase, global emission to peak as soon as possible and rapid emission reductions (UN, 2015). European commission has already 2011 proposed a target for renewable energy in EU's overall energy mix to be $20 \%$ by 2020 (EREC, 2011). This increases the need for wind and solar energy which are inconsistent energy forms which have negative effect on electric grid stability (Götz et al., 2016). This opens a need for long term large capacity electric energy storage.

One option for energy storing and electric grid stabilizing is the power-to-gas (PtG). The PtG works as a link between the power grid and the natural gas grid by converting electric energy to gas suitable to gas grid. The $\mathrm{PtG}$ is a two-step process, where firstly $\mathrm{H}_{2}$ is produced by water electrolyser and secondly $\mathrm{H}_{2}$ together with $\mathrm{CO}_{2}$ is converted to $\mathrm{CH}_{4}$ by a methanation reaction (dena German Energy Agency, 2015).

Even though the PtG process is usually driven as much as possible due to high investment costs, sometimes process might need to be shutdown. In the literature shutdowns and start-ups have been presented only for individual parts of the PtG process e.g. electrolysis (Eichman et al., 2014). Literature seems to lack of publications and research related to full dynamic simulations of PtG process from electric grid to gas grid. Experimental results for this process have been presented for example by $(\mathrm{Zu}-$ berbüler et al., 2016). In this work, all parts of the process are modelled individually and the control logics for startups and shutdowns are linked to work together as a plantlevel coordinating system. The main aim of this paper is to demonstrate the potential of using a dynamic process simulator in the development of such control logics for a PtG process. To the authors' best knowledge, the presented detailed simulation results are the first of a kind in the literature.

\section{Methodology}

Since start-ups and shutdowns are inherently dynamic operations, a dynamic simulation platform, Apros $\AA$ (Savolainen et al., 2016; Silvennoinen et al., 1989; Tähtinen et al., 2016; Weiss et al., 2016) was used. The schematic flowsheet of the modelled PtG plant is shown in Figure 1. The PtG plant modelled in this work has three $3 \mathrm{MW}$ electrolysers connected to power grid. Their electrical power consumption follows the grid frequency. Hydrogen and oxygen produced by electrolysis are flowing through interim storages before usage for buffering and compression reasons. Hydrogen is used in methanation while in this study oxygen does not have any specific usage. $\mathrm{CO}_{2}$ for methanation comes from a constant flow power plant flue gases by MEA absorption. The captured $\mathrm{CO}_{2}$ has also an interim storage mainly for compression reasons. The produced $\mathrm{CH}_{4}$ from methanation reactor is compressed to natural gas grid pressures in a compression station.

All individual process components are described in upcoming subsections. More detailed description of the process model can be found from the study by

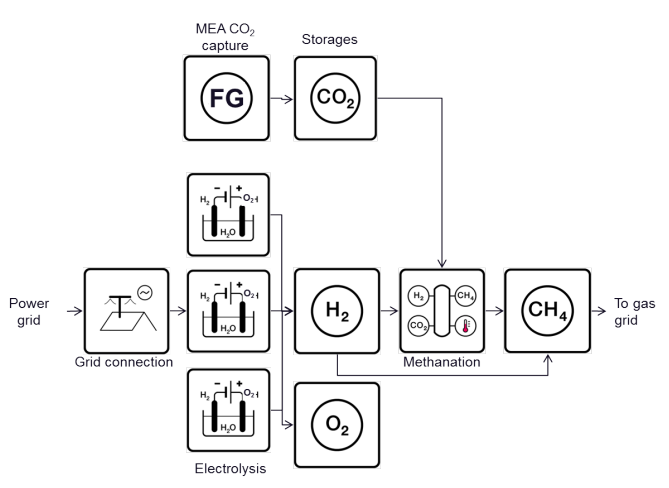

Figure 1. Flowsheet of the modelled PtG process. 
Savolainen et al. (2016).

\subsection{Power grid connection}

The power grid connection block takes grid frequency in hertz as an input. Based on grid frequency the connection block gives an output electrical power for the electrolysers. This power is determined by user given droop curve in Figure 2. Maximum output power for one electrolyser was set to $3 \mathrm{MW}_{e}$.

\subsection{Electrolyser}

Three alkaline electrolysers working at 1 bar pressure and $70^{\circ} \mathrm{C}$ nominal temperature were used in this study. Electrolyser modelling was done with current-voltage (IV) curve from (Zhou and Francois, 2009). IV-curve is used to calculate the output molar flows of hydrogen and oxygen. Also released heat from the electrolyser cells is calculated and the needed cooling circulations with heat exchangers and major liquid and metal thermal masses are modelled. The alkaline electrolyser model was validated with industrial scale data and the relative errors were found to be within $\pm 5 \%$ (Savolainen et al., 2016).

\subsection{Interim gas storages}

Interim gas storages for $\mathrm{H}_{2}, \mathrm{CO}_{2}$ and $\mathrm{O}_{2}$ have similar construction in them, only pressure levels and the numbers of compression stages are different. In this study, the most important interim storage is the one for hydrogen. Interim $\mathrm{H}_{2}$ storage has three different pressure levels connected to each other with semi-isothermal compression trains. More accurate description of interim $\mathrm{H}_{2}$ storage can be found from (Tähtinen et al., 2016). The purpose of the interim storage is to stabilize gas flows from fluctuating sources to processes that need constant inlet gas flow, to provide storage for possible excess gas and to fill the gap when gas production is low. For example, hydrogen flow from electrolysis can be fluctuating heavily when electrolysis is used to stabilize power grid frequency or when intermittent energy sources are used.

\subsection{Methanation}

Hydrogen and carbon dioxide are mixed before entering to the methanation reactor. $\mathrm{CO}_{2}$ feed from interim storage is controlled to achieve stoichiometric molar ratio (4:1 $\mathrm{H}_{2}: \mathrm{CO}_{2}$ ) for the methanation feed flow. A constant mixed

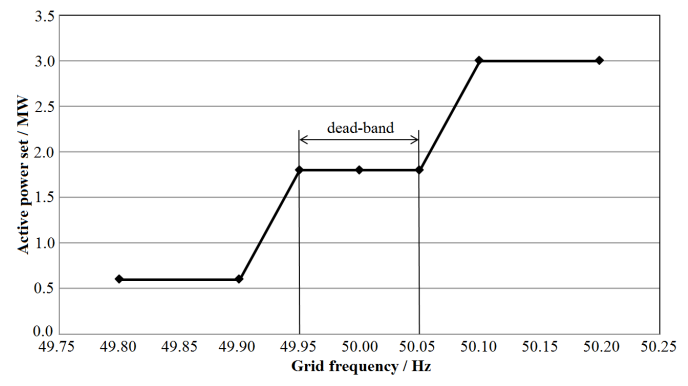

Figure 2. Droop curve of power grid connection. feed flow from storages used is approximately $0.20 \mathrm{~kg} / \mathrm{s}$. Fixed bed methanation reactor has average pressure of 6.3 bar and the maximum temperature is controlled to be $550^{\circ} \mathrm{C}$ by steam cooling. A part from the output flow is recirculated back to the methanation reactor inlet. The amount of recirculation flow is controlled to by the quality of the gas produced in methanation. Aim for the $\mathrm{CH}_{4}$ concentration on dry basis is set to 96 mol-\%. The recirculated flow is cooled and the steam is condensed off before recirculation compressor. This flow is mixed with the gas mixture from the interim gas storages. The methanation reactor model was validated with laboratory measurements and was found to be in good agreement with them as indicated in Figure 3 below.

\section{5 $\mathrm{MEA} \mathrm{CO}_{2}$ capture}

Carbon dioxide used in methanation is captured from flue gas flow with a monoethanolamine (MEA) scrubber whose model is based on (Rao and Rubin, 2002). The MEA scrubber model calculates energy needs (reboiler duty, blower and pump electric energy) for $\mathrm{CO}_{2}$ capture. Assumption in this model is that $\mathrm{CO}_{2}$ source has excess production and is not limiting factor of the process model. This model has no actual dynamics but it can be used in the future to determine possible heat integrations of the process.

\section{6 $\mathrm{CH}_{4}$ compression}

Product gas from methanation is cooled and steam is condensed off. After water removal the methane concentration is high enough for the natural gas grid ( $>95$ mol- $\%$ ). Methane is compressed to the natural gas grid pressure of 54 bar with a compression train consisting two compressor stages and water driven heat exchangers after them.

\section{Control sequences}

In this section, control logics for start-up and shutdown sequences are described. Specific control logics for each process component are presented.

\section{1 $\mathrm{CH}_{4}$ compression}

Product gas from methanation is cooled and steam is condensed off. After water removal the methane concentra-

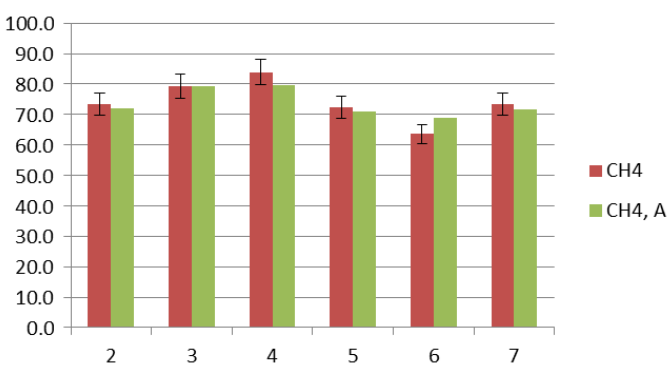

Figure 3. Comparison of product gas $\mathrm{CH}_{4}$ mol-\% between laboratory measured $\left(\mathrm{CH}_{4}\right)$ and simulated $\left(\mathrm{CH}_{4}, \mathrm{~A}\right)$. 
tion is high enough for the natural gas grid (>95 mol-\%). Methane is compressed to the natural gas grid pressure of 54 bar with a compression train consisting two compressor stages and water driven heat exchangers after them.

\subsection{Start-up}

The start-up is initiated from a cold state. Cold state startup is the base case for start-up and it includes every step that is happening in a start-up. The stat-up order of equipment and the equipment specific routines as well as their inter-links are described in the following list.

\subsubsection{Power grid connection}

Since the time constants in power electronics are much smaller than in other process components there are not specific dynamic steps taken.

\subsubsection{Methanation reactor}

In its standby state, the methanation reactor is filled with hydrogen to prevent unwanted reactions between nickel catalyst and $\mathrm{CO}_{2}$ (Jürgensen et al., 2015). During the start-up methanation reactor is firstly heated up to at least $275^{\circ} \mathrm{C}$ temperature before $\mathrm{H}_{2}$ and $\mathrm{CO}_{2}$ mixture can be fed in. This heating is done with an electric heater. During the start up the product quality does not meet the conditions for natural gas grid and recirculation is used to increase the product quality. Recirculation compressor starts when $\mathrm{H}_{2}-\mathrm{CO}_{2}$ mixture starts to feed in the reactor. Even though the methane quality is low during the start-up some of the methanation product is fed to the natural gas grid. This is due to the fact that the hydrogen concentration up to $5 \mathrm{vol}-\%$ is acceptable in the natural gas grid (Melaina et al., 2013). This also prevents pressure to rise in the methanation reactor uncontrollably high. Steam cooling of the reactor starts when methanation reactions cause temperature at the reactor inlet to rise close to $550^{\circ} \mathrm{C}$.

\subsubsection{Electrolysers}

The three alkaline electrolysis units are identical and their start-up routine is the same. When alkaline electrolyser is shut off it is filled with nitrogen gas to prevent catalyst oxidation (Øystein et al., 2010). During start-up incoming water pushes nitrogen out from the cells. Water feed is opened when power feed from grid connection starts. Electric current cause's water to split into hydrogen and oxygen and the hydrogen prevents catalyst oxidation now.

Alkaline electrolysis start-up takes from 30 to $60 \mathrm{~min}-$ utes (Øystein et al., 2010). In literature it is not specified how long it takes for removing the purge gas and how long it takes to heat up the electrolyser. For this reason in our model production restrictive part is taken to be the heating up of the equipment and nitrogen removal is not modelled. Production of $\mathrm{H}_{2}$ and $\mathrm{O}_{2}$ gases in the model starts instantaneously when power feed is turned on. This needs further validation as it is still unclear how production behaves during start-up. Part of the hydrogen should be used to prevent catalyst oxidation. The power feed to the electrolysers is started when temperature of methanation reactor is $230^{\circ} \mathrm{C}$.

\subsubsection{Interim gas storages}

Interim gas storages have a control to keep the pressure at the inlet at the constant level. This control becomes active whenever there is an inlet flow causing the pressure rise. Outlet of the storages opens when downstream part of the process is ready for this. In other words, the interim hydrogen storage outlet opens when the methanation is heated up to the "ignition" temperature (at least $275^{\circ} \mathrm{C}$ ) of methanation reaction. Next, $\mathrm{CO}_{2}$ feed opens to fulfil stoichiometric molar feed ratio and finally $\mathrm{CO}_{2}$ feed from MEA to interim storage is opened when storage outlet has been opened.

\subsection{5 $\mathrm{CH}_{4}$ compression}

The compression train in $\mathrm{CH}_{4}$ compression unit is turned on when methanation reactor is heated up. Feed to the natural gas grid can be started at this point even though $\mathrm{CH}_{4}$ concentration is low and $\mathrm{H}_{2}$ concentration is high. $\mathrm{CH}_{4}$ compression is set to keep the pressure in the methanation reactor at 6.3 bars.

\subsection{Shutdown}

Shutdown sequence is a reverse process to start-up with some changes in actions of some process components.

\subsubsection{Methanation reactor}

Methanation reactor shutdown starts by extinguishing methanation reactions in the reactor. This is done by stopping $\mathrm{CO}_{2}$ feed. Only pure hydrogen is feed to the methanation reactor until its $\mathrm{H}_{2}$ concentration is close to $95 \mathrm{~m}$ percent. Recirculation is closed and high $\mathrm{H}_{2}$ concentration gas mixture is fed to the natural gas grid. When there is no $\mathrm{CO}_{2}$ in the reactor it is safe to turn the cooling off. Additional cooling is not done for the reactor to reach the ambient temperature; this cooling is done only by natural convection.

\subsection{2 $\mathrm{CH}_{4}$ compression}

Shutdown of methanation happens by decreasing the $\mathrm{CO}_{2}$ concentration in the reactor. This causes decrease in the methnation reactions. The concentration of $\mathrm{CH}_{4}$ decreases and $\mathrm{H}_{2}$ increases. This is thought to not be a problem as it is allowed to feed some $\mathrm{H}_{2}$ to the natural gas grid. $\mathrm{CH}_{4}$ compressors first follow the inlet pressure and when $\mathrm{H}_{2}$ fed to the methanation reactor is closed are $\mathrm{CH}_{4}$ compressors also closed.

\subsubsection{Interim gas storages}

$\mathrm{CO}_{2}$ feed to methanation is first to close during shutdown as explained in previous section. MEA capture is kept running until pressure vessels in $\mathrm{CO}_{2}$ storage are full. $\mathrm{H}_{2}$ feed to methanation is open until desired $\mathrm{H}_{2}$ concentration in methanation reactor is reached. Compressors in $\mathrm{H}_{2}$ and $\mathrm{O}_{2}$ storages close as the feed from electrolysers stops. 


\subsubsection{Electrolysers}

The model of alkaline electrolyser doesn't contain any real volume to where purge nitrogen could be fed during shutdown. For this reason the electrolyser shutdown is done by shutting the power feed from the power grid connection. The power feed is turned off when $\mathrm{H}_{2}$ interim storage is full. $\mathrm{H}_{2}$ storage is filled before total shutdown so that start-up of electrolyser and methanation can be done simultaneously. Cooling water feed is working as long as heat is produced in the electrolyser. Cooling to ambient temperature is left to be done by natural convection. In future development should be done to get the purge nitrogen feed for the model. Nitrogen gas flow works also as cooling agent which is beneficial for the electrolyser as oxidation is less severe in lower temperatures.

\section{Results}

In the experiment the start-up and shutdown sequences were activated by the operator, not process conditions. The start-up sequence was initiated after 10 minutes of steady down period. Star-up sequence was driven for 5 hours and 50 minutes. This time was long enough to stabilize the methanation process as can be seen from Figure 4 .

The shutdown was started after the PtG plant had stabilized to normal mode, at the 6 hour mark in Figure 4-6. As can be seen, the shutdown process is much faster as electrolysers and methanation reactor were left to cool down only by natural convection. In total, 4 hours of shutdown was simulated to see at least some cooling in electrolysers, see Figure 5. Cooling of the methanation reactor was minimal due to the high total mass of the equipment and the insulation effect of steam cooling jacket.

Cold start-up of the methanation reactor is the slowest part of the PtG plant start-up. From the literature we did not find any time values for the methanation reactor's cold start-up. Heating ramp used in the simulations was selected so that too high temperature gradients would not happen, since a high temperature gradient could have negative effect on the catalyst durability. In the simulations the highest temperature gradients were found to happen when $\mathrm{H}_{2}$ and $\mathrm{CO}_{2}$ mixture feed was opened and closed, at 3 and 6 hour marks respectively in Figure 3. During start-up average temperature of the methanation reactor experienced $100^{\circ} \mathrm{C}$ drop in 3 minutes. Reason for this is the start-up of the recirculation and $\mathrm{CH}_{4}$ compression units. Inlet gas is not heated before coming to the reactor and sudden rise on the flow cools the reactor. Also, rapid changes in temperature can result from changing reaction mixture composition. In other words, if the feed $\mathrm{H}_{2}: \mathrm{CO}_{2}$ molar ratio deviates from the stoichiometric value of $4: 1$, the reaction speeds and thus released heat is affected.

Fast changes in the gas feed causes also pressure fluctuations, which are detrimental for the durability of catalyst, in the methanation reactor, are seen at the lower part of Figure 4. During the start-up the methanation reactor experienced a pressure drop of 3.4 bars in a bit over 1.5 minutes.

During the start-up and steady operation of electrolysers the power from the power grid connection was fluctuating because grid frequency control was participated in. This did not cause high temperature gradients in the electrolyser and was found to be possible operation mode. Total heating up time for the electrolysers was 1 hour and 43 minutes, see Figure 5, top. Reason for long heating up time is the $1.8 \mathrm{MW}$ average electric power used during the heating up period. Start-up period was also used for power grid frequency controlling. Start-up times from 30 to 60 minutes mentioned in literature could be achievable with maximum electric power of $3 \mathrm{MW}$.

The alkaline electrolysis $\mathrm{H}_{2}$ and $\mathrm{O}_{2}$ productions start instantaneously when electric power is switched on and the effect of temperature has low impact to this, Figure 5 lower part. This part of the electrolyser model needs further investigation and development.

Flow from the methanation to the natural gas grid has high changes in quality, measured as $\mathrm{CH}_{4}$ molar- $\%$, during the start-up and shutdown. During start-up this flow changes from a high $\mathrm{H}_{2}$ concentration to high $\mathrm{CH}_{4}$ concentration (and during shutdown vice versa), as can be seen in Figure 6. As mentioned in previous sections this is thought to be acceptable because the natural gas grid can take up to 5 vol- $\%$ of hydrogen. Changes are happening relatively fast ( $<30 \mathrm{~min})$ and the flow is also lower than during the steady operation.

Above 1 vol- $\% \mathrm{CO}_{2}$ concentration was observed during the start-up for a time interval of a bit less than 30 minutes. Reason for this is the same as for high temperature and pressure swings in the methanation: compressors for the recirculation and the natural gas grid compression having too fast start-up ramp. Other than this the product gas quality has found to be good during start-up and shutdown.

\section{Conclusions and future work}

This paper presented a simulation-aided control development study for a PtG plant. In the results we showed example simulations of plant start-up and a shutdown. The first contribution of the paper was to show the potential of using dynamic simulation in identifying control development needs in the PtG process. The second contribution was the actual development needs, namely:

- $\mathrm{CH}_{4}$ compression start-up to minimize the amount of $\mathrm{CO}_{2}$ to the natural gas grid and to minimize the temperature and pressure swings in the methanation reactor.

- Nitrogen purge for alkaline electrolyser.

- Effect of temperature in the alkaline electrolyser.

In the future, partial shutdown and start-up sequences will be implemented into the model, allowing for example the 

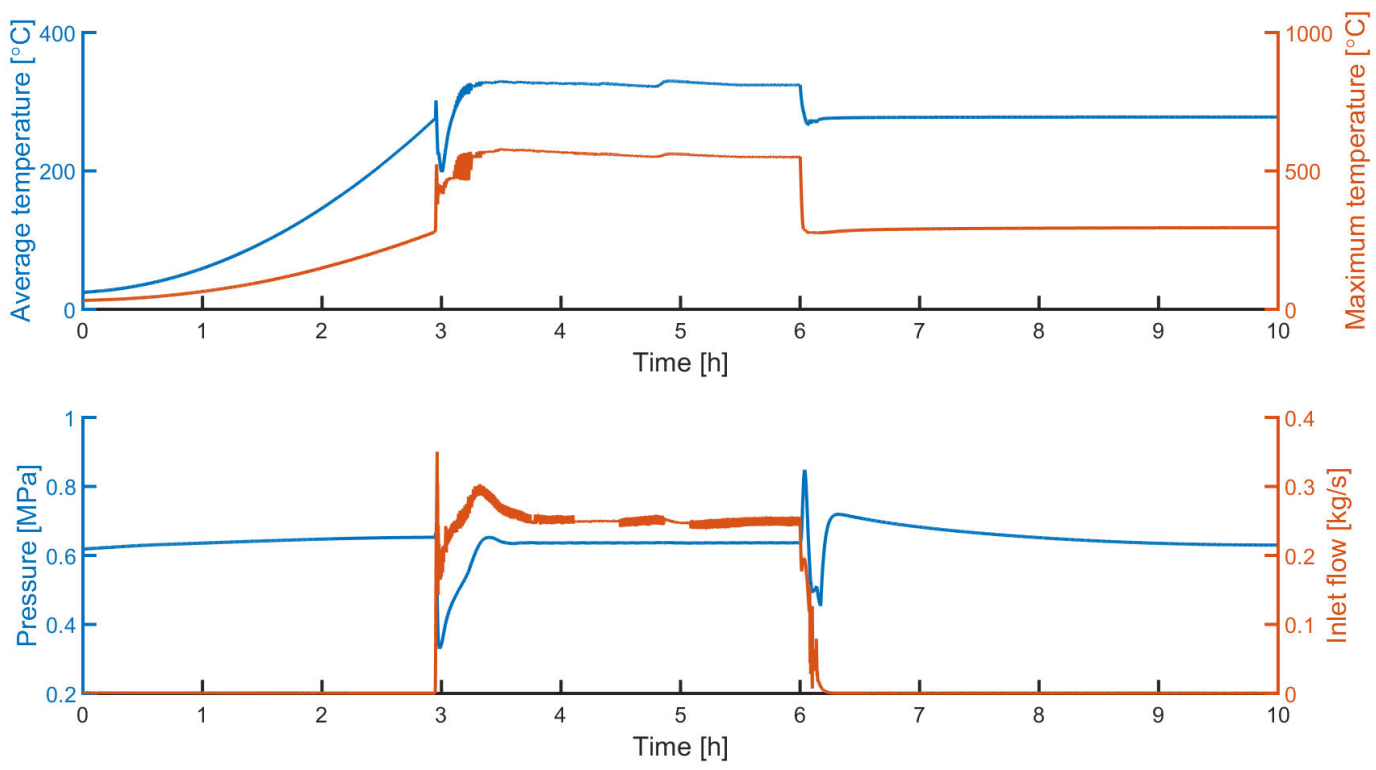

Figure 4. Changes on average and maximum temperature (upper) and pressure and inlet gas flow in the methanation reactor during start-up and shutdown sequences.
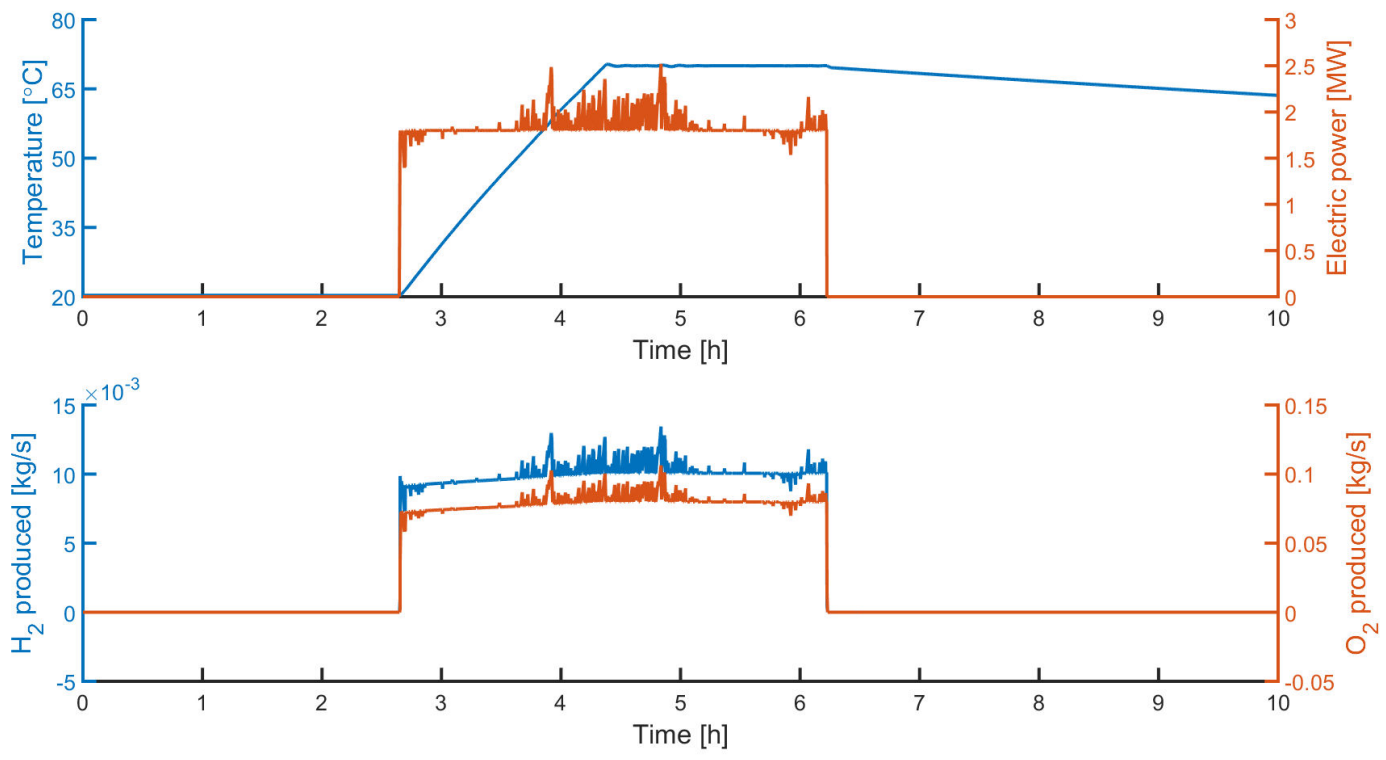

Figure 5. Temperature and inlet power changes (upper) and changes on $\mathrm{H}_{2}$ and $\mathrm{O}_{2}$ production (lower) during start-up and shutdown sequences of one electrolyser. 


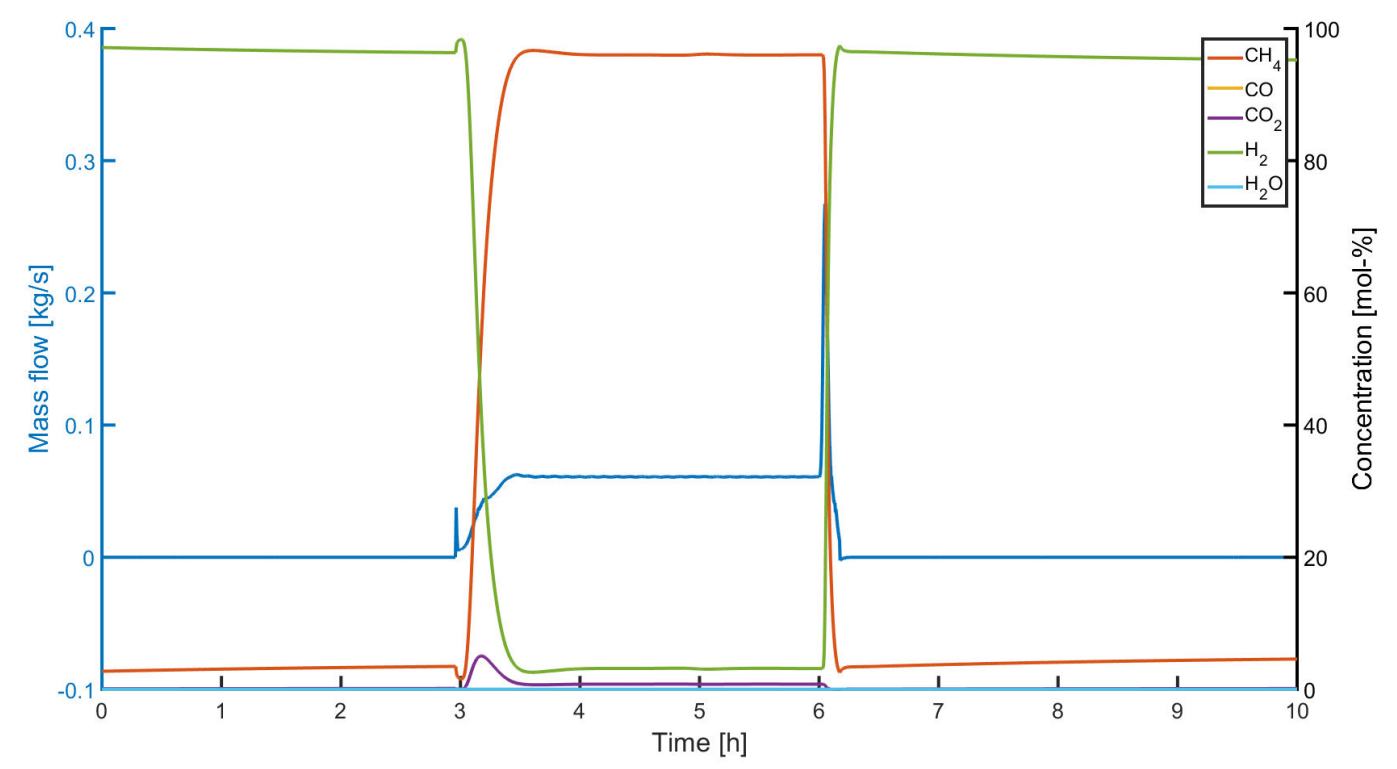

Figure 6. Mass flow and component-wise concentration changes in gas flow to natural gas grid during start-up and shutdown sequences.

methanation to be shut down when either hydrogen or carbon dioxide storage is empty. Also, optimization could be done e.g. on how to do the electrolysis start-up, with maximum electric power vs. frequency control mode used in this study. Also, heat integrations are planned to be done for the model and their effect to the start-up and shutdown logics need to be studied.

While this study presented only one case study, it can be argued that the PtG plant wide dynamic simulation aided control development approach taken here has wider applicability. Firstly, the process under study is not in any way uncommon to the chemical industry as it contains typical unit operations such as electrolysis, reactors, mixing, separations and storage. Secondly, the unit operations models utilized in the study are validated. Thirdly, as the results show, we were able to identify control development needs using the approach. Thus, it stands to reason that a similar approach is likely to be applicable and useful in other cases as well.

\section{Acknowledgment}

The authors gratefully acknowledge the public cofinancing of Tekes, the Finnish Funding Agency for Innovation, for the 'Neo-Carbon Energy' project under grant number 40101/14.

\section{References}

dena German Energy Agency. Power to gas system solution. opportunities, challenges and parameters on the way to marketability., 11 2015. URL http://www.powertogas. info/fileadmin/content/Downloads/Brosch\% C3BCren/dena_PowertoGas_2015_engl.pdf.

J. Eichman, K. Harrison, and M. Peters. Novel Electrolyzer
Applications: Providing More Than Just Hydrogen. Sep 2014. doi:10.2172/1159377. URL http://www.osti. gov/scitech/servlets/purl/1159377.

European Renewable Energy Council EREC. Mapping renewable energy pathways towards 2020, 2011.

Manuel Götz, Jonathan Lefebvre, Friedemann Märs, Amy McDaniel Koch, Frank Graf, Siegfried Bajohr, Rainer Reimert, and Thomas Kolb. Renewable power-to-gas: A technological and economic review. Renewable Energy, 85:1371 - 1390, 2016. ISSN 0960-1481. doi:https://doi.org/10.1016/j.renene.2015.07.066. URL http: //www.sciencedirect.com/science/ article/pii/s0960148115301610.

Lars Jürgensen, Ehiaze Augustine Ehimen, Jens Born, and Jens Bo Holm-Nielsen. Dynamic biogas upgrading based on the sabatier process: Thermodynamic and dynamic process simulation. Bioresource Technology, 178:323 - 329, 2015. ISSN 0960-8524. doi:https://doi.org/10.1016/j.biortech.2014.10.069. URL http://www.sciencedirect.com/science/ article/pii/s0960852414014916.

Marc Melaina, Olga Sozinova, and Michael Penev. Blending hydrogen into natural gas pipeline networks: A review of key issues, 012013.

Anand B. Rao and Edward S. Rubin. A technical, economic, and environmental assessment of amine-based co2 capture technology for power plant greenhouse gas control. Environmental Science \& Technology, 36(20):4467-4475, 2002. doi:10.1021/es0158861. URL http://dx.doi.org/ 10.1021 /es 0158861 . PMID: 12387425 .

Jouni Savolainen, Lotta Kannari, Jari Pennanen, Matti Tähtinen, Teemu Sihvonen, Riku Pasonen, and Robert Weiss. Operation of a PtG plant under power scheduling, 032016. 
E. Silvennoinen, M. Hänninen, K. Juslin, K. Juslin, Valtion teknillinen tutkimuskeskus, K. Porkholm, and O. Tiihonen. The APROS Software for Process Simulation and Model Development. Tutkimuksia (Valtion teknilli-nen tutkimuskeskus). Technical Research Centre of Finland, 1989. ISBN 9789513834630. URL https:// books. google.fi/books?id=qBV9AAAACAAJ.

Matti Tähtinen, Teemu Sihvonen, Jouni Savolainen, and Robert Weiss. Interim $\mathrm{H} 2$ storage in power-to-x process: Dynamic unit process modelling and dynamic simulations case process and modelling principles, 032016.

United Natios UN. Paris agreement, 122015.

Robert Weiss, Jouni Savolainen, Pasi Peltoniemi, and Eero Inkeri. Optimal scheduling of a P2G plant in dynamic power heat and gas markets, 032016.

Øystein Ulleberg, Torgeir Nakken, and Arnaud Eté. The wind/hydrogen demonstration system at Utsira in Norway: Evaluation of system performance using operational data and updated hydrogen energy system modeling tools. International Journal of $\mathrm{Hy}$ drogen Energy, 35(5):1841 - 1852, 2010. ISSN 0360-3199. doi:https://doi.org/10.1016/ j.ijhydene.2009.10.077. URL http: / / www.sciencedirect.com/science/ article/pii/s0360319909016759.

Tao Zhou and Bruno Francois. Modeling and control design of hydrogen production process for an active hydrogen/wind hybrid power system. International Journal of Hydrogen Energy, 34(1):21 - 30, 2009. ISSN 0360-3199. doi:https://doi.org/10.1016/j.ijhydene.2008.10.030. URL http: //www.sciencedirect.com/science/ article/pii/s0360319908013141.

U Zuberbüler, M Specht, H Jachmann, S Schwarz, B Stürmer, B Feigl, and S Steiert. Project: automatic operation of a power-to-gas plant based on simulated timetables in scenarios with high shares of renewable power and the development of a smart gas grid injection concept, 032016. 